\title{
COSTA BRAVA, LOS RETOS URBANÍSTICOS DEL TURISMO \\ DE MASAS. La huella de la ciudad jardín y algunos principios racionalistas en el tejido turístico de masas
}

\author{
Carolina Ramos Caravaca \\ Universitat Politècnica de Catalunya. Departament d'Urbanisme i Ordenació del Territori. \\ Director: Joaquin Sabaté Bel
}

\section{RESUMEN}

El turismo de masas plantea un nuevo reto urbanístico a mitad del siglo XX. La Costa Brava adopta el modelo de ciudad jardín, utilizado durante el turismo de élite, e introduce aportaciones del Movimiento Moderno. La costa es un territorio de experimentación donde la ciudad jardín y el urbanismo moderno convergen.

Pese a las dificultades de los primeros años de ensayo, los nuevos tejidos muestran parámetros propios, y la relación de los edificios con el entorno marca una clara diferencia con la ciudad anterior.

En los años 80 se replantea el urbanismo en la costa corrigiendo deficiencias del crecimiento previo, pero sin tener en cuenta las especificidades de la ciudad turística. En la actualidad se mantiene este mismo planteamiento sin reconocer la identidad de los tejidos y arquitecturas desarrolladas durante la etapa pionera del urbanismo turístico.

Palabras clave: turismo de élite, turismo de masas, ciudad jardín, malla turística. 
ID_INVESTIGACIONES

\begin{abstract}
Mass tourism becomes a new challenge for mid-20th century urbanism. Costa Brava adopts the garden-city model from elite-tourism and introduces Modern Movement contributions. The coast is used as an experimental territory where two different models converge, the garden city and the functionalist one.

Despite the difficulties of the early years, the new urban tissues have specific characters, and the relationship between the buildings and their context show a clear difference respect the previous city.

In the eighties the new municipal plans face the deficiencies generated by the fast growth not taking into account the specificities of the touristic city. This same approach is currently extended, not recognizing the identity of tissues and architectures of the pioneering period of the tourist urbanism.
\end{abstract}

Key words: elite tourism, mass tourism, garden city, urban tourist grid. 


\section{LA COSTA BRAVA}

La Costa Brava se sitúa en el extremo norte de la costa catalana que hace frontera con el sur de Francia. Su paisaje se caracteriza por el contraste entre el mar y la montaña, se combinan los macizos que irrumpen repentinamente con el mar, las pequeñas calas que se esconden entre las rocas, las laderas de los montes que resguardan las largas playas de la fuerte Tramontana, y las sinuosas bahías que dejan respirar la llanura que se abre entre la topografía. Un paisaje cuya belleza se debe a su variedad, a su irregularidad, y a sus múltiples componentes. Es también el sin cesar de curvas topográficas lo que la distingue y hace fácil su identificación al lado de las llanuras que forman la costa del Maresme al sur. O la inmensa bahía pantanosa que se extiende al norte de la frontera francesa y forma la costa del Languedoc-Roussillon.

El clima mediterráneo que baña de sol, brisa y luz las estaciones veraniegas hasta bien llegado el invierno, complementa el paisaje y la vegetación de la costa convirtiéndola en foco de atención para diversas civilizaciones, viajeros y turistas.

La presencia humana en la Costa Brava data de fechas muy lejanas. Sus propiedades como territorio rico en aguas y cultivos, bien comunicado por mar, y protegido por el relieve, la convierten en un territorio cuya historia se remonta a varios siglos antes de Cristo, como el caso de las ruinas de Ampurias, donde se concentran vestigios de una ciudad griega y una romana (siglos I, II a.C.) en el mismo emplazamiento.

Entre los siglos $\mathrm{V}$ y $\mathrm{X}$, coincidiendo con el periodo oscuro que se vive entre la caída del Imperio Romano, las conquistas visigóticas y musulmanas, y la entrada de la Edad Media, las ciudades se abandonan y pasa a establecerse la vida y el trabajo en el medio rural. Será al final de este periodo cuando vuelvan a constar agrupaciones de casas formando núcleos que más tarde se convierten en ciudades. Hacia los siglos XI y XII, ya existen estos pequeños núcleos edificados alrededor de una parroquia o un convento, es a partir del siglo XIV cuando la mayoría de estos asentamientos empiezan a protegerse de los ataques enemigos y a construir las murallas en su perímetro. $Y$ es entonces cuando aparecen las ciudades medievales de la Costa Brava, como es el caso de gran parte de las principales ciudades históricas que permanecen en la actualidad, Blanes, Lloret, Tosa, Sant Feliu de Guíxols, Palamós, o Roses. 
Entre los siglos XVI y XVIII, las ciudades más expuestas a amenazas de invasión, o asaltos piratas por mar, se convierten en fortalezas, ciudadelas, y su costa se llena de Torres de vigilancia y baluartes, especialmente en los núcleos situados en el Alto Ampurdán ya que su posición cercana a la frontera los hace puntos más estratégicos. Es el caso de núcleos como Roses o Palamós, que se convierten en ciudadelas militares, acompañadas por rabales pesqueros frente al mar. Hay también otros casos como la villa de Cadaqués, que pese a su carácter pesquero y agrícola, debe fortificarse en exceso por el ataque constante de piratería e invasión y la no posibilidad de huida por tierra.

La relación con el mar ha sido siempre un tema de controversia para los habitantes de la Costa Brava, ya que por una parte ha dado alimento y ha facilitado el comercio y la relación naval internacional, pero por el contrario fue también durante varios siglos la puerta y el ataque de piratas y pueblos invasores.

A partir del siglo XVIII con la disminución de ataques piratas, empiezan a surgir los primeros barrios de pesca y posteriores puertos comerciales de las ciudades interiores. Existen por ejemplo, San Antoni de Calonge, barrio pesquero de Calonge y de Palamós, Calella de Palafrugell o Tamariu, barrios de pescadores de Palafrugell, L'Estartit, barrio pesquero de Torroella de Montgrí , La Escala, barrio pesquero de San Martín de Ampurias, o Port de la Selva, barrio pesquero de Selva de Mar.

Durante el siglo XIX, el comercio marítimo internacional especialmente con las Américas, la construcción de naves, o la exportación de productos como el corcho, producen un crecimiento de la economía, y consecuentemente de la inversión en obras de urbanismo (se hacen planes urbanísticos de ensanches y ampliación de las ciudades) e ingeniería de muchas de estas villas medievales. Por tanto se urbanizan calles, se reconstruyen puertos y muelles, y definitivamente se derriban murallas y se construyen paseos. Ejemplos de este momento de crecimiento industrial y comercial, son ciudades como San Feliu de Guíxols que se convierte en capital.

La Costa Brava había dependido siempre de recursos naturales como la agricultura, la ganadería, o la pesca, y es destacado su papel en la industria del corcho que ha sido uno de los motores principales de su economía a lo largo de los siglos. Pero con la irrupción del 
turismo de masas a mitad de s. XX, toda su industria y su perspectiva de crecimiento se centró exclusivamente en este nuevo fenómeno.

\section{EL TURISMO DE ÉLITE EN LA COSTA BRAVA}

El turismo hace que la relación de las personas con el mar cambie completamente, y pase de ser un lugar temido por el desconocimiento o el ataque pirata, o simplemente lugar relacionado con la industria pesquera o el comercio marítimo, a ser un lugar deseado para disfrutar del tiempo libre. El mar se redescubre como un elemento beneficioso y curativo, y ejerce el papel que previamente habían ejercido los balnearios de aguas termales. Con la particularidad de ser disfrutado estacionalmente.

En el caso español, el primer turismo aristócrata de Madrid se orienta hacia la costa Cantábrica, más cercana. Claro ejemplo son las lujosas ciudad balneario de San Sebastián o Santander. O en las costas Gallegas el ejemplo de las instalaciones balnearias de La Toja. También es conocida la cultura balnearia en la la costa andaluza sobretodo en la ciudad de Málaga, o en las costas valencianas con instalaciones cerca de las playas del Cabañal, La Malvarosa o Las Arenas.

Pese a la poco conocida existencia de cultura balnearia relacionada con el turismo de élite en las costas catalanas, existen recientes estudios que destacan su importancia: "En la costa catalana funcionaban medio centenar de establecimientos de baños (Bailly- BaillierieRiera, 1935), muestra evidente de una alta densidad de ocio marítimo, muy por encima de la que presentaban otros lugares de la costa peninsular, como por ejemplo la cantábrica, valorada en muchas investigaciones como la más importante de España" (Mercedes Tatjer 2009. En los orígenes del turismo litoral: Los baños de mar y los balnearios marítimos en Cataluña). Es por tanto relevante el papel de la costa catalana como referencia de cultura balnearia.

En la ciudad de Barcelona se conocen establecimientos termales desde inicio de s. XIX. Inicialmente se crean con fines médico-terapéuticos, y entrada la segunda mitad de siglo, se extiende la cultura balneario hasta que aparecen una docena de centros termales en la propia Barcelona (Baños Astillero, Sant Miquel, etc.) 
La pieza clave para comprender la extensión de la cultura balnearia fuera de las ciudades importantes es la aparición del ferrocarril. Sus primeras instalaciones a partir de 1848 (Línia Barcelona-Mataró) permiten ampliar el radio de construcciones de balnearios de mar. De esta manera, en las primeras costas cercanas a Barcelona abastecidas de línea de ferrocarril aparecen estaciones balnearias como el Balneario Colón (Caldes d'Estrac) los Baños Titus (Arenys).

Mientras que a finales de s. XIX (1872-1910) en Barcelona y alrededores crecía el número de termas : Los Baños Orienales, La Florida, San Sebastián, Neptuno, Tritón.. En las zonas accesibles por el ferrocarril se empezaban a crear lugares de reposo y veraneo para las clases adineradas. La mencionada Caldetes (Caldes d'Estrac), Sitges, o la Playa de San Salvador cerca de Tarragona empezaron a atraer a la burguesía de Barcelona, y en definitiva, a participar del movimiento turístico relacionado con la cultura balneario.

A principios del siglo XX también aparecen las primeras urbanizaciones de costa en la Costa de Poniente (Costa Daurada), por ejemplo en Sitges (urb. Terramar 1933), en Vilanova i la Geltrú (Ribes Roges por J-Ma Guibernau 1917), o en Calafell y el Vendrell (urb. Y hotel balneario Comarruga 1922). De la misma forma se encuentran emblemáticos ejemplos en la Costa Brava, comentados a continuación.

\subsection{Turismo balneario en la Costa Brava}

El primer movimiento hacia las costas procedente de la provincia de Barcelona, se dirigió hacia las zonas más cercanas y de un acceso más cómodo. Así pues las primeras costas expuestas a la visita de la burguesía barcelonesa a partir del último tercio del s. XIX fueron la Costa de Poniente (Sitges), o el tramo norte que se extiende por la actual comarca del Maresme (Caldes d'Estrac). Todas las localizaciones provistas de línea de ferrocarril.

El relieve de la Costa Brava y el difícil acceso de las infraestructuras ferroviarias retrasa su popularidad entre las clases adineradas de la provincia de Barcelona. Fue disfrutada, inicialmente, por algunas familias bien estantes de la misma provincia de Gerona, o de la burguesía barcelonense que dedicaba un poco más de tiempo en llegar hasta los puntos más accesibles como Blanes (San Feliu de Guíxols o Palamós requerían cambio de tren y 
estación). No es hasta cerca de 1900 que se empiezan frecuentar los baños termales y de aguas de mar en esta zona.

Hay una primera etapa entre 1850 y 1919 aproximadamente, más modesta, de acercamiento a la costa de las familias acomodadas de provincia que disfrutan de baños más rudimentarios en el mar.

Los primeros establecimientos de baño se encuentran en los núcleos situados cerca de estaciones ferroviarias, en Lloret, datan de 1904 los Baños Ventura, y en Sant Feliu de Guíxols se conocen los baños la Pedrera en 1898-1899. Se habla también en los textos de Josep Pla de los baños cabina situados en Calella de Palafrugell, también en la zona de Roses, ya que llegan familias acomodadas de Figueres o Girona. Es así el ferrocarril una pieza clave en la distribución del turismo de élite antes del uso estandarizado del automóvil.

La segunda etapa llega a partir de la 1a Guerra Mundial (1914-1918). En este periodo la clase burguesa se enriquece fuertemente gracias a la neutralidad de España en el conflicto y a la exportación de productos nacionales (también se produce una inflación de los precios de los productos básicos en un $40 \%$, hecho que intensifica el empobrecimiento de la clase obrera).

La burguesía enriquecida convierte los destinos balnearios en lugares de ocio donde no faltaran los paseos marítimos, jardines botánicos, termas, hoteles de lujo y los casinos. Los baños también se sofistican y se complementan con instalaciones deportivas.

A principio de los años 20 , la burguesía catalana se empieza a interesar por el paisaje natural fuera de las aglomeraciones urbanas en lugares aislados y el contacto directo con la costa y con el mar. Empiezan entonces a construirse las primeras urbanizaciones en forma de ciudad jardín en el perímetro de las ciudades que funcionaban como balneario, se inicia la construcción de chalés con vistas al mar. Este modelo vacacional que se inicia en la época del turismo de élite marcará fuertemente, como veremos a continuación, el planeamiento posterior de los núcleos de costa. Esta segunda etapa finaliza con la llegada de la Guerra Civil Española (1936-1939).

Es por primera vez en 1908 cuando la Costa Brava se denomina por su nombre, será durante las charlas de Ferran Agulló (Yvette Barbazà, 1966), y no será hasta 1924 que se 
promocionará la Costa Brava como tal, llamándose anteriormente Costa de Levante.

A partir de los años 20, empieza a nacer la consciencia de las posibilidades de explotación turística del litoral. En 1919 se organiza el Primer Congreso de turismo de Cataluña, resultado de la iniciativa de la Societat de Forasters de Barcelona, que tiene por objetivo estrechar las relaciones entre las diferentes entidades relacionadas con actividades turísticas: Sindicats d'iniciativa o Atraccions de forasters, compañías de servicios ferroviarios o marítimos, empresas hoteleras, ayuntamientos de pueblos de belleza natural o monumental susceptibles de ser foco turístico, etc. (Annie Unland, 1996)

No es hasta 1927 que el turismo en la Costa Brava se empieza a popularizar en la provincia de Barcelona gracias a la influencia de los grupos excursionistas. En 1928 el sr. J. Marill sistematiza las excursiones marítimas y organiza los "Viatges Blaus" 1928 . También se inician a partir de 1929 las excursiones en autocar des de Barcelona a Blanes, Lloret y San Feliu de Guíxols. (Yvette Barbazà, 1966)

Otra fecha trascendente en el inicio de la promoción turística de la Costa Brava es 1929. En este año se realiza la Exposición Universal en Barcelona, que juntamente con la Exposición Iberoamericana realizada en Sevilla el mismo año, consiguen concentrar la atención internacional. Las diferentes asociaciones de organismos relacionados con el turismo y la promoción de la Costa Brava que empezaban a nacer, vieron en estas exposiciones la gran oportunidad de dar a conocer el territorio más allá de las fronteras. "Portarà a les terres peninsulars un moviment considerable d'estrangers, venint en plan turístic" (Revista de Palafrugell "Baix Empordà" referencia 02/02/1929). De esta forma se inicia una campaña publicitaria para asegurar el movimiento generado en Barcelona por la Exposición Universal.

En el municipio de Palafrugell, implicado directamente en la promoción del desarrollo turístico de la Costa Brava, se publica también en 1929 una Guía de la Costa Brava, y se inicia la organización de exposiciones artísticas, de fotografía, o se propondrá la divulgación de imágenes de la costa en revistas extranjeras (revista alemana de Ueberseepost de Leipzig.)

En 1931 la Generalidad de Cataluña consideraba ya la planificación del litoral como una cuestión prioritaria . En 1935, se realiza la Conferencia de La Costa Brava firmada por todos los alcaldes de sus municipios. (Annie Unland 1996). En el año 1935, también, un decreto de la Generalidad de Cataluña crea El Patronat de la Costa Brava, comisión encargada de 


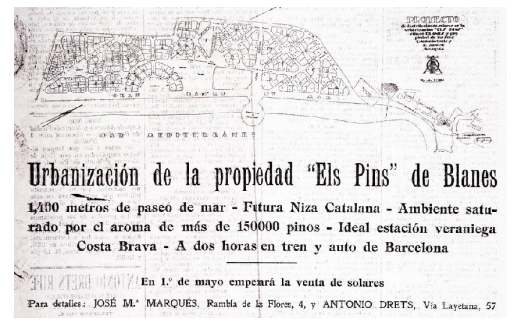

Blanes, Els Pins 1925-1926 velar por las bellezas naturales y arquitectónicas de la Costa Brava y tomar las iniciativas pertinentes para la atracción del turismo extranjero. Se toma, definitivamente, consciencia desde la administración del potencial y negocio turístico. (B. Cervera i Flotats, A. Alonso de Molina 1978).

\subsection{Algunas experiencias de ciudad jardín y ciudad balneario}

Pese a la adaptación tardía de la Costa Brava al turismo de élite, y su carácter más local, existen ejemplos de ciudades con balneario y sus cercanas urbanizaciones de costa en forma de ciudad jardín que merecen mencionarse:

\section{Blanes y Lloret cultura de ciudad balneario, y el proyecto de ciudad jardín "Els Pins"}

En Blanes y Lloret, las situadas más al sur de la Costa Brava cercanas al paso del ferrocarril por el Maresme, también disfrutan del incipiente turismo de élite. Sus fachadas marítimas empiezan a ser convertidas en paseos donde se suceden las construcciones de chalés neo-clásicos, y antiguas casas se transforman en casas de veraneo señorial. En Lloret aparecen los primeros baños "Ventura" en 1904, y las primeras salas de proyecciones cinematográficas en 1906.

Al igual que pasa en el caso de Sant Feliu, durante los años 20, aparecen las primeras urbanizaciones tipo ciudad jardín con vistas al mar alrededor de las ciudades de moda. En el caso de Blanes, se proyecta la urbanización "Els Pins" (Josep Reixach y Emili Serra 19251926), situada en la extensión de pineda frente a la playa anexa al núcleo de Blanes (zona de S'Abanell). El conjunto de carácter neo-clásico, "noucentista" preveía una gran avenida marítima de 1300 m de largo, y otra gran avenida de circunvalación de 1660 m de largo.

El proyecto se presenta en el Boletín Oficial de la Provincia de Barcelona como la Niza catalana. Se contó con la aprobación del ayuntamiento, y en 1926 se iniciaron las primeras obras. Pese a la diluida lectura que se puede hacer sobre alguna de sus trazas o primeras edificaciones, el proyecto nunca se finalizó ni llegó a tomar suficiente forma y fue irrumpido por la cercana Guerra Civil. 


\section{Sant Feliu de Guíxols: Sant Elm y S’Agaró}

San Feliu de Guíxols es, seguramente el caso más claro y emblemático de ciudad industrial de costa adaptada a ciudad balneario. Su crecimiento industrial, la "febre del suro" generan un fuerte desarrollo urbanístico y de infraestructuras de la ciudad; ferrocarril propio, puerto, fábrica de gas, red eléctrica.

Su accesibilidad por ferrocarril, y su posición al sur de la Costa Brava, cercana a la provincia de Barcelona, la convierten en una de las más frecuentadas por la burguesía de Barcelona. Y los elementos que la transforman en ejemplo de ciudad balneario son los siguientes:

- El paseo del mar, los chalés y el casino: Un plano del arquitecto Martí Sureda aprobado en 1859 marca la alineación definitiva con el paseo del mar, y la nueva burguesía empieza a construirse chalés noucentistas siguiendo el trazo del paseo delante del mar. En ese mismo paseo años más tarde aparecerá el nuevo casino de Sant Feliu de Guíxols, Casino La Constanaza , por el arquitecto General Guitart 1888.

- El balneario: Desde 1875 se conoce la existencia de casetas de baño al sur de la playa de Sant Feliu de Guíxols, que más tarde fueron convertidas gracias a Baldomer Ribot i Roc Sala i Oliu (1893-1919) en el Balneario Guixolense 1893, conocido como Els Banys d'en Baldomero, bajo la dirección técnica de la construcción de General Guitart y Lostaló.

Pasada la Primera Guerra Mundial (1942-45), los Banys d'en Baldomero quedaron prácticamente en desuso, y el arrendatario barcelonés Pere Rius i Calvet compró la propiedad de los antiguos baños y promovió un nuevo conjunto acompañado de la extensión del paseo marítimo hasta su emplazamiento a pie de la montaña de Sant Elm. Esta rehabilitación realizada por el arquitecto Joan Bordàs i Salella se llamará Los baños de Sant Elm 192022, y se convirtió en uno de los balnearios de más renombre del mediterráneo. El nuevo baño de Sant Elm ofrecía instalaciones de baño de mar caliente, duchas, baños de vapor, instalaciones deportivas trampolines, pasarelas, club de waterpolo, restaurante, bar, etc.

- La ciudad jardín Sant Elm: Frente al fervor que despierta la cultura balneario entre la burguesía, y su deseo de reposar en lugares cada vez más aislados de las aglomeraciones y con vistas al mar, aparecen las primeras urbanizaciones en forma de ciudad jardín.

En 1922 aparece la urbanización de Sant Elm, en la parte superior de la misma montaña

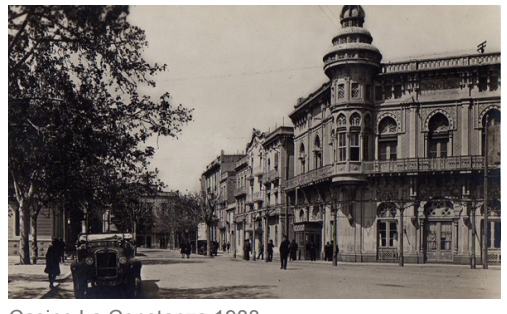

Casino La Constanza 1988

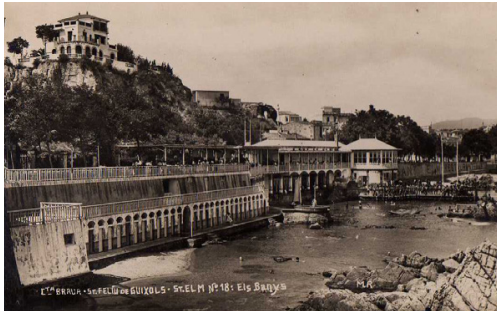

Baños de Sant Elm 1920-22

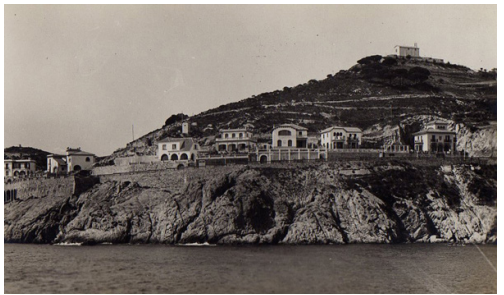

Urbanización Sant Elm 1922 


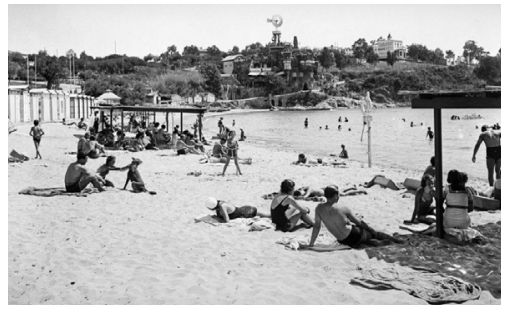

S'Agaró Parque de Atracciones 1915-1935
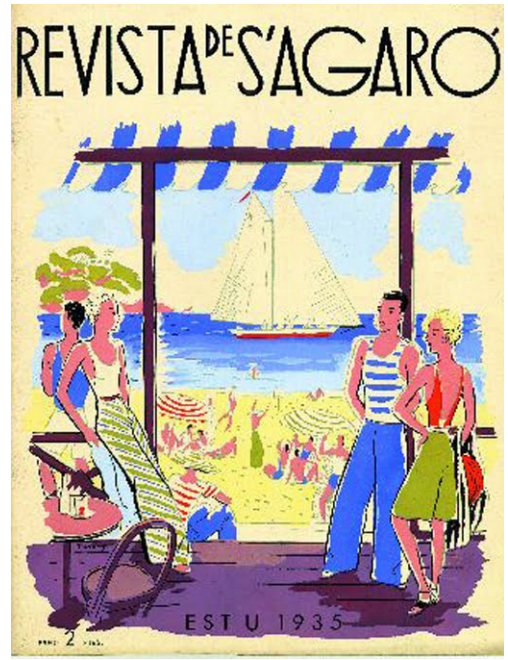

Revista de S'Agaró 1935

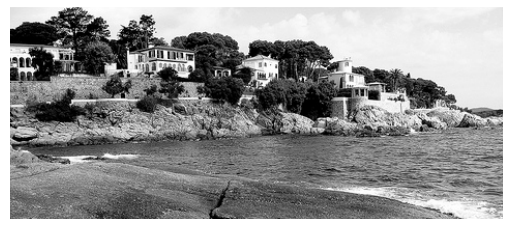

Urbanización S'Agaró 1920-24 donde se sitúa el balneario, y también promocionada por Pere Rius i Calvet, la Urbanización de Sant EIm (1922-1931) se convierte en una de las primeras urbanizaciones destinadas al turismo balneario.

- La ciudad jardín de S'Agaró: Se sitúa a un extremo de la playa de Sant Pol, anexa al núcleo de St. Feliu. El fenómeno tiene su origen en 1916 por la compra de una parcela de terreno por parte del industrial gerundense J.Ensesa i Pujadas, quien fue ampliando su propiedad hasta que decidió dividirla en parcelas para crear un vecindario. En 1920, Ensesa compra las casetas de baño que ya existían en el extremo oriental de la Playa de Sant Pol, y definitivamente en 1924 el hijo del propietario construye la primera residencia, Senya Blanca. J.Ensesa i Gubert. Es entonces cuando aparece la figura del arquitecto noucentista Rafael Masó, y el proyecto da un giro hacia una futura ciudad de vacaciones residencial que con el más apurado detalle y exquisito gusto consigue atrapar la atención de la élite internacional.

Un acuerdo entre J. Ensesa y la compañía de transporte de los "Viatges Blaus", consigue que s'Agaró aparezca en todos los panfletos publicitarios de las excursiones que se dirigían a la Costa Brava. En poco tiempo con la publicación de la lujosa revista "S'Agaró" destinada al turismo de élite internacional, se consigue la afluencia deseada.

En 1932 se inaugura el famoso Hotel "La Gavina" que ha albergado a las más altas clases sociales hasta nuestros tiempos. (En 1935 ya eran 14 las residencias que formaban parte de la urbanización). En poco tiempo S'Agaró se convierte en un fenómeno del turismo de élite, un lugar de afluencia de clases altas.

\section{Palamós y La Fosca}

Palamós también vive un gran periodo de crecimiento económico gracias al auge de la industria corchera, se convierte así en una de las ciudades más importantes de l'Empordà a mitad de s. XIX. A partir de 1850 su expansión urbanística permite la creación de extensos ensanches frente al mar. $Y$ en 1887 es abastecida por el ferrocarril, factor que influye en el papel que desenvuelve dentro de la cultura balneario de la época.

La Playa de la Fosca situada al norte del núcleo de Palamós, y algo más desvinculada del 
conjunto urbano, se convierte también en un centro de reposo de la élite de la sociedad catalana de la época. Las familias adineradas de Palamós empiezan a construir sus chalés a partir de inicio de s. XX, pero es el propietario Remigi Tauler (artífice del Hotel Jeroglífic en la misma playa), quien da impulso al desarrollo turístico de La Fosca. Así pues cuando en la playa sólo existía alguna residencia de lujo y el conjunto Jeroglífico, se presenta el proyecto del Hotel Miramar, un inmenso complejo turístico, que no solamente albergaba plazas hoteleras sino que contemplaba zona de balneario, chalés, centros deportivos y otras actividades.

Finalmente el proyecto no se realizó, sólo se terminó la carretera que unía la Fosca con Palamós en 1928. En lugar del Hotel Miramar, en 1934 se construyó el hotel Rocafosca, situado al sur del antiguo emplazamiento. En esta Playa también se encontraba el Mas Juny, propiedad de Josep María Sert, en la cual se albergaron célebres personalidades de la época.

\section{Calella de Palafrugell y Llafranch}

A final de s. XIX también en la costa de Palafrugell se inicia el transporte en coche "público", cuyos fundadores, Ribot, Font i Artigas fundaran en 1910 la famosa SARFA (compañía de autobuses que conectará toda la costa desde 1936 hasta la actualidad).

La presencia de baños en Calella de Palafrugell se remonta a inicio de s.XX Francesc Estrabau (rentista y alcalde de Palafrugell conocido como el Caixa) promociona los "Banys d'en Caixa", que solo tienen una durada de siete años.

En Llafranch, playa que sólo estaba frecuentada por agricultores y pescadores hasta el momento, se inicia la construcción de la primera casa del paseo marítimo en 1871. Fue el primer núcleo construido por la burguesía de Palafrugell para pasar los domingos. (Josep Pla 1941, Guia de la Costa Brava. ). El primer turismo balneario de Llafranch se puede conocer gracias a los escritos de Josep Pla. (El Quadern Gris, crònica de l'any 1918) Según el escritor, los verdaderos veraneantes eran los forasteros americanos que venían en la temporada entre el 19 de julio y el 30 de agosto. Según Pla, a los primeros veraneantes no les gustaba el mar, "era un estiueig de gent vestida, de fredolics".

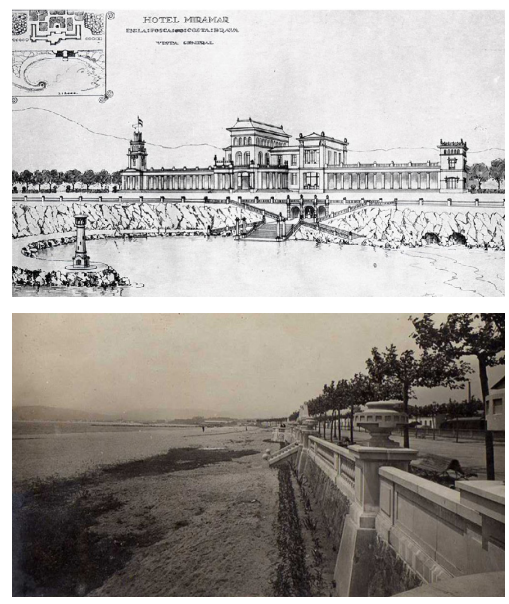

Urbanización S'Agaró 1920-24

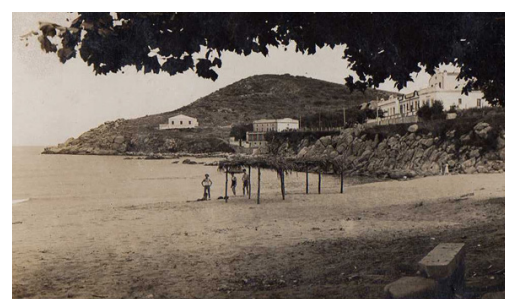

La Fosca 1934 


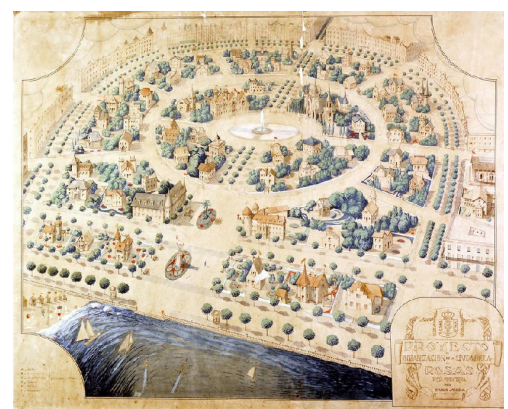

Proyecto Ciutadella 1918
Hacia los años 20/30, Palafrugell también se implicó en campañas de promoción turística viendo en ese incipiente deseo de costa un posible motor económico. En 1932 se creó la asociación de Fomento del turismo. Y Entrados los años 30 se mejoran la infraestructura y las comunicaciones, y aumenta la visita de la burguesía barcelonesa la costa de Palafrugell. Muchos de estos parajes naturales se descubren gracias a las recomendaciones de actividades marítimas propuestas por el centro excursionista de Cataluña.

\section{Roses, proyecto de ciudad jardín de La Ciutadella de Roses}

En el núcleo de Roses consta la presencia de casetas de baño en la Playa del Rastrell desde 1880. El tipo de veraneantes que frecuentaban estos establecimientos pertenecían también a las clases adineradas de la sociedad, pero de tipo bastante local. El registro del archivo del ayuntamiento de Roses permite constatar la naturaleza de estos visitantes; abogados, cónsules, notarios o comerciantes parte destacada pero productiva de la sociedad, dejando atrás los primeros veraneantes de élite pertenecientes a rentistas o aristócratas. (Josep M. Barris i Ruset. Roses o a recerca de la zona grisa 1999-2008)

Son también conocidos los Baños de La Mercè en Roses, frecuentados por los habitantes de Figueras. (Mercedes Tatjer 2009).

En Roses también se plantearon varios proyectos de ciudad jardín para albergar a esa clase burguesa que se disponía a disfrutar de la cultura balneario.

El proyecto inicial de Narcís Amigó fue desestimado para dar paso a la propuesta más conocida que Nicolás María Rubió y Tudurí propone en 1918, y que sería promovida por Joan Adolf Mas Yebra, promotor barcelonés. Rubió y Tudurí planteó una trama urbana radial a partir de una plaza central, rodeada de ocho manzanas y un gran paseo exterior, el cual delimitaba dos sectores, el núcleo central con vivienda unifamiliar aislada en planta baja y uno o dos pisos de altura, y sobre la anilla exterior proponía una zona un poco más densa de edificaciones plurifamiliares de tres o cuatro plantas rodeadas de jardín. (Propuesta innovadora tratándose de una ciudad jardín justo a inicios del siglo XX). Además de equipamientos utilitarios que también planteaba el proyecto anterior, como la escuela, la 
iglesia, etc., Rubió y Tudurí, planteó la construcción de un gran hotel, y un casino, y además la solución del frente marítimo la resolvía con un gran paseo marítimo de 40 metros de ancho. Es un proyecto completo de ciudad con todos sus servicios utilitarios y de recreo. Rubió y Tudurí hace casi una propuesta premonitoria en cuanto al fenómeno turístico posterior.

El proyecto se aprobó por el Ministerio de Gobernación en 1919, cuya extensión y afectación se modificó en 1929 por el arquitecto Francesc Ferriol. Se planteó también abastecer a Roses con línea y estación de ferrocarril. Pero la falta de recursos económicos para derribar las murallas, y el inicio de la Guerra Civil, sentencian el abandono definitivo de todas estas propuestas.

\section{La ciudad jardín de Platja d'Aro' ${ }^{1}$}

El caso de Platja d'Aro es algo diferente ya que no existe un núcleo histórico previo consolidado. En 1928 tiene lugar el proyecto de ciudad jardín de Josep Esteve Corredor (Arquitecto que colabora con Rafael Masó en el caso de S'Agaró).

Pero también existe un proyecto de Josep Lluís Sert y Torres Y Clavé que se presenta en el año 1929 como la primera propuesta con preocupación social para una ciudad de vacaciones, el Poble d'estiueig a la Costa Brava. Es de las primeras veces en la historia que se piensa en el veraneo de la clase trabajadora. Este proyecto, que combina elementos típicos de la ciudad balneario de principio de siglo y tipologías innovadoras para la conversión a la democratización de las vacaciones, servirá para dar paso a la creación del grupo GATCPAC, y la posterior Ciutat del Repós i les Vacances de Castelldefels.

\section{LA LLEGADA DEL TURISMO DE MASAS (a partir de mitad de siglo XX)}

A finales del s. XIX y principio del XX, la Costa Brava ya se re-descubre como un territorio turístico, pero será a partir de mediados de siglo XX cuando éste se convierte en un

1 El caso de Platja d'Aro se explica en el artículo publicado en el IV Seminario de Investigación en Urbanismo 2011 "Platja d'Aro. Focus de la reflexió sobre el pas del turisme d'elit al repòs de la classe treballadora". 
fenómeno tan fuerte que transformará definitivamente tanto su paisaje humano como el natural.

La Guerra Civil Española (1936-1939) interrumpe fuertemente la evolución de los incipientes destinos frecuentados por el turismo de élite.

A nivel internacional, la Segunda Guerra Mundial (1942-1945), tiene un efecto similar en el resto de Europa. El turismo apenas progresa pero empieza a cambiar su carácter hacia un público más amplio. La introducción de las vacaciones pagadas y el automóvil permite a un abanico más extenso de gente introducirse en la actividad del turismo. Además, en la Costa Brava intervienen otros elementos que incidirán definitivamente en su éxito internacional.

Durante los años 40 y 50 en la Costa Brava aumenta la presencia de artistas, pintores, escritores, escultores, e intelectuales, que ejercen un papel propagandístico muy importante a escala mundial. Por ejemplo el pintor catalán J. Vilallonga que se interesa por el paisaje de la costa a inicios de s. XX, el escritor Josep Pla, o más tarde el mismo Salvador Dalí. Es indudable que ayudan en la promoción internacional de la Costa Brava.

Otro foco propagandístico se centró en la producción cinematográfica procedente de Hollywood que se llevó a cabo en algunos de los lugares más bellos de la Costa Brava como Tossa (Pandora y el holandés errante 1950, con Ava Gadner), S’Agaró (Suddenly, Last Summer con Liz Taylor) o Tamariu- Llafranch (Sombras Acusadoras 1958 con Richard Todd y Anne Baxter.

Con la llegada del turismo masivo, el territorio de la Costa Brava sufre un intenso cambio. En la segunda mitad del siglo XX, gran parte del terreno rural de la costa se convierte en urbanizado y la economía de la zona se centra exclusivamente en el sector turístico dejando de lado la productividad agrícola anterior. Los núcleos urbanos ya consolidados se transforman hacia un aumento de densidad y un crecimiento de las alturas en las primeras líneas de mar. El territorio que rodea estos núcleos es invadido por urbanizaciones de vivienda unifamiliar dispersa en el caso de terrenos montañosos y mallas turísticas de bloques de apartamentos en los tramos llanos frente al mar.

Mientras que el terreno anexo a los núcleos es usado para la creación de segunda residencia, los núcleos tradicionales absorben la actividad hotelera y los servicios turísticos 


\section{ID_INVESTIGACIONES}

en la medida que son capaces. La mayor parte del desarrollo turístico se produce con respecto a un núcleo previo, sólo existen dos casos en los que el crecimiento turístico puede considerarse ex-novo, Ampuriabrava y Platja d'Aro.

Es importante destacar el papel que ha tenido la topografía irregular de esta costa en el fenómeno turístico, ya que durante varias décadas ha podido filtrar y retrasar su aparición en los lugares menos accesibles, y de esta manera ha condicionado fuertemente la ubicación y crecimiento de las nuevas construcciones vinculadas al fenómeno. Es también relevante si comparamos la afectación de construcciones en el territorio en la Costa Brava con algún emplazamiento de más fácil acceso como la Costa Levantina, donde el impacto turístico fue mucho mayor.

Frente a la inminente aparición del fenómeno turístico de masas, el 12 de Mayo de 1956 se aprueba en España la 1a Ley del suelo para proporcionar un marco legal a todas las nuevas construcciones. El objetivo inicial de la Ley fue evitar la especulación del suelo y la irregularidad en el proceso de urbanización. Y lo hará a través del control en el planeamiento urbanístico, el régimen del suelo, y la ejecución de las urbanizaciones. Sus herramientas de acción en principio serán: un Plan Nacional de Urbanismo, Planes Provinciales y Planes Generales Municipales. Finalmente sólo estos últimos serán ejecutados y puestos en práctica, y se acompañarán de los Planes Parciales y los Proyectos de Urbanización. Es entonces a partir de 1956 cuando empiezan a surgir los primeros Planes Generales Municipales de costa.

El tejido turístico de la Costa Brava puede separarse en dos periodos que marcan unas diferencias notables en su asentamiento y morfología:

_ Primer periodo 1956-1980: Comprende el desarrollo urbanístico entre la Ley del Suelo 1956 y el Real Decreto 1385/ 1978, por el cual se traspasan todas las competencias de la Administración del Estado a la Generalitat de Cataluña. Durante este periodo se desarrolla la 1a serie de Planes Generales Municipales de costa.

_ Segundo periodo a partir de 1980: Periodo de reflexión y crítica a las actuaciones 
anteriores. A partir de los años 80 se realiza la 2a serie de Planes Generales Municipales, que trataran de frenar la explotación del medio natural expandida en el periodo anterior.

Desde el gobierno del estado se escogía un Gobernador Civil, que dirigía cada Comisión Provincial de Urbanismo, organismo que se encargaba de aprobar definitivamente cada Plan General Municipal.

Por otro lado, cada ayuntamiento tenía un papel relevante, encargado de las aprobaciones iniciales y las posteriores modificaciones una vez presentada la aprobación definitiva. Finalmente debido a la elección y sustitución de los alcaldes municipales por mano del Gobernador civil Provincial, las decisiones de los ayuntamientos estaban bajo el poder y dependían totalmente de la Comisión. (Ignasi Bosch Reitg 1978)

En 1978 arquitectos y urbanistas critican las primeras actuaciones urbanísticas en la Costa Brava en las ponencias del "Debat Urbanístic de La Costa Brava". "A més, les Comissions Provincials d'Urbanisme són molt més sensibles a les pressions polítiques que no ho serien els Ajuntaments democràticament elegits. La realitat ens ha demostrat que tota actuació de la Comissió Provincial d'Urbanisme HA ESTAT CATASTRÔFICA PER A LA COSTA BRAVA i per tant necessita una radical transformació i reestructuració fent-la menys polititzada i més representativa." (Ignasi Bosch Reitg, Debat Costa Brava 1978, Ponencia 4, Com ha estat planejada la Costa Brava?)

En el caso de la provincia de Gerona la Comisión Provincial de Urbanismo proyectará la mayoría de los Planes Generales Municipales para los municipios de costa, siguiendo un mismo modelo. En todos ellos se preve una adaptación en los núcleos y una gran reserva de territorio al incipiente turismo de masas, y todos ellos parten de la ciudad jardín. Destaca el papel del arquitecto Josep Claret Rubira, como Director de la Oficina Técnica de Urbanismo.

Josep Claret Rubira, arquitecto licenciado en Barcelona en 1933, pasa los últimos años de carrera en contacto con miembros de un incipiente GATCPAC, y empieza a trabajar con J.L. Sert. En 1931 se asocia al grupo y se convierte en el único miembro gerundense del GATCPAC. Es clara su influencia racionalista, pero él no llega nunca a compartir todos los principios teóricos del Movimiento Moderno, especialmente su universalidad. Claret defiende el tradicionalismo y la vernacularidad de cada lugar, admira fuertemente a arquitectos noucentistas como Rafael Masó. 


\section{ID_INVESTIGACIONES}

En la figura de Josep Claret Rubira confluyen dos corrientes teóricas que muchas veces se contraponen a lo largo de la historia, el Racionalismo y el "Noucentisme". Mezcla que se dará en muchos de los arquitectos que intervendrán en las operaciones de costa.

Como veremos a continuación, estos planes dirigidos por Claret Rubira, se basaran en el único modelo utilizado para crear ciudad de vacaciones: la ciudad jardín. Pero a su vez introducirán nuevos principios racionalistas que mutaran el modelo original hasta transformarlo en un resultado diferente. $Y$ de esta forma aparecen la mayoría de los tejidos urbanísticos que se mantienen en la actualidad en la Costa Brava.

\subsection{Primer Periodo: los primeros PGM (1956-1962)}

A partir de 1956 empiezan a surgir los primeros Planes Generales Municipales,en todo el litoral español, por ejemplo, el PGM Benidorm 1956.

En la Costa Brava rápidamente aparecen los Planes de los municipios de costa afectados por el turismo: I'Escala 1956, Lloret 1957, Roses 1958, Blanes 1958, Torroella de MontgríEstartit 1959, Palamós i Sant Antoni de Calonge 1959, Platjad'Aro- S'Agaró 1959, PalafrugellCalella- Ilafranch- Tamariu 1961, etc,

Se prevé una ampliación de los núcleos que albergue el futuro turismo de masas. Se amplía la red viaria y se califican algunas zonas urbanas. Y como ya se ha mencionado, el modelo de ciudad jardín se utiliza de base. Es un modelo que varía la densidad según se acerca y se aleja del casco urbano existente. Según la ocupación y el tamaño de parcela se distinguen diversos tipos de ciudad jardín que gradualmente pierden intensidad. De la normativa que rige los parámetros en todas sus intensidades de pueden destacar brevemente las características siguientes:

_ Se permite la vivienda unifamiliar y colectiva.

_ Se marca un máximo de 2 plantas y media de altura. (Se entiende como media un semi-sótano o un ático que no sobrepase el $50 \%$ de la superficie edificada en las plantas inferiores). 
_ Se marcan unas distancias mínimas con los límites de parcela que son, en general, 3m con los límites y 6 con las edificaciones vecinas.

Los planes de todos los municipios de costa se estructuran de una manera muy similar y comparten características, sólo se distinguen por pequeñas variaciones en porcentajes o nomenclaturas.

Los tipos de ciudad jardín que se plantean son los siguientes:

_ Ciudad Jardín Intensiva: Son zonas marcadas cerca de los núcleos existentes, las ocupaciones oscilan entre el 55-70\% (construcción principal + auxiliar), y la parcela mínima en muchas ocasiones es de $0 \mathrm{~m} 2$ (no hay límite)

-Ciudad Jardín Semi- Intensiva: Es la segunda franja de ciudad jardín que empieza a perder densidad, las ocupaciones máximas están entre el 40-46\% (construcción principal + auxiliar), y la parcela mínima es de 400m2.

_ Ciudad Jardín Extensiva: Se sitúa en los extremos del núcleo más en contacto con las zonas rurales, las ocupaciones son menores marcando máximos de $32 \%$ (construcción principal + auxiliar), y las parcelas mínimas están entre los 600 y los $1000 \mathrm{~m} 2$.

_ Parque Urbanizado y Bosque Urbanizado: Estas dos calificaciones no se utiliza en todos los núcleos, ya que se relacionan con zonas de interés natural . La ocupación y el tamaño de parcela son algo más restrictivos en cuanto a mantener la baja densidad. Suelen pedir parcelas mínimas de entre 5000 y 10000 m2 y ocupaciones de entre 5 y $15 \%$. Este modelo comparte la baja densidad de la ciudad jardín de élite.

_ Zona de reserva: Son grandes porciones de terreno destinadas a abastecer una posible demanda de extensión de la ciudad que supere lo previsto como ciudad jardín. Se permite: vivienda unifamiliar siguiendo las pautas de la Ciudad Jardín Extensiva con mínimos de parcela de $1000 \mathrm{~m} 2$, vivienda colectiva siguiendo las mismas pautas pero añadiendo $500 \mathrm{~m} 2$ a la parcela por cada vivienda añadida. También se permite la construcción de núcleos urbanos con un mínimo de 8 viviendas. La zona de reserva lo que hace, por tanto, es ampliar fuertemente la previsión de crecimiento destinado al turismo de una forma algo ambigua. 

_ Zona Libre Permanente: Finalmente, la Zona Libre Permanente es el ámbito sin calificar, que en la mayoría de casos no aparece ni grafiado en los planos, pero forma, igualmente, parte del municipio. Estos terrenos, en principio, no son edificables, pero se pueden aprobar construcciones bajo el permiso de La Comisión Provincial.

En resumen, la clasificación del suelo, no deja claro un ámbito protegido en el que se evite completamente la construcción. Las previsiones de abastecimiento turístico crean inmensas zonas urbanizables.

\section{La crítica a los Planes de los 50-60. (Ponencia: Debate Costa Brava 1978)}

Una de las fuertes deficiencias de esta serie de Planes era la poca rigurosidad en cuanto a coeficientes y la no protección del medio rural dejando abierta la posibilidad de construcción. Además, estos planes fueron modificados y manipulados por Planes Parciales, que influyeron morfológicamente los tejidos.

A finales de los años 70 una fuerte crítica se extendió en el mundo del urbanismo, culminando en el caso de la Costa Brava en las ponencias recogidas en el Debate Costa Brava 1978, en el que numerosas personalidades se lamentaban de la descontrolada situación y exigían un replanteo del urbanismo en la costa. Algunas de las críticas expuestas en el debate hacia los primeros planes fueron las siguientes:

- Se produce un crecimiento en forma de mancha de aceite, en todas direcciones y con continuidad absoluta del núcleo generador. Sin estudio ni reconocimiento de las particularidades del territorio.

- No se realizan estudios sobre protecciones concretas de los tejidos históricos de los núcleos antiguos. Y por tanto éstos no son respetados.

- Se autorizan alturas superiores a las tradicionales en los núcleos, hecho decisivo en la substitución de las edificaciones históricas. No está previsto dentro del plan, se aprueba a través de ordenanzas.

- Se legalizan actuaciones al margen del planeamiento, situación que provoca cierto descontrol. 


\section{ID_INVESTIGACIONES}

- Se califican como edificables grandes extensiones de suelo en expectativa, con independencia de las reales previsiones de crecimiento.

\section{Innovaciones de los planes. Influencia del Racionalismo}

Los primeros PGM son la base de las mallas turísticas y de las urbanizaciones que se extienden por la Costa Brava. Pese a la fuerte crítica recibida, estos planes son la guía de la mayor parte de la construcción turística realizada en la Costa Brava, ya que fue una época de gran desarrollo. Y por tanto merecen ser estudiados de nuevo sin la fuerte visión negativa que se extendió tras su efecto.

Se escoge el modelo de ciudad jardín, el único modelo conocido hasta el momento para urbanizar terrenos rurales y convertirlos en lugares de vacaciones. Una elección que remonta al turismo de élite, pero que ahora hacía frente a un nuevo fenómeno nunca vivido hasta el momento, el incipiente turismo de masas. Así pues se escoge como base la ciudad jardín, pero se introducen algunas claves innovadoras que cambiarán radicalmente el carácter de estos nuevos crecimientos.

Principalmente se introducen dos puntos básicos en la transformación. Los dos puntos siguen la línea de acercar el turismo a un mayor número de gente, en definitiva de democratizar las vacaciones. $\mathrm{Y}$ de esta manera dar paso al turismo de masas:

_ Se aumentan las densidades: Cuando se plantea la Ciudad Jardín Intensiva, la parcela mínima se reduce a $0 \mathrm{~m} 2$, y la ocupación máxima sumando la construcción principal y la auxiliar se eleva a un $70 \%$. Son parámetros que distan fuertemente de la ciudad jardín clásica. En el caso de S'Agaró 1916, las parcelas mínimas estaban sobre los 5000m2 y la ocupación sobre el $5 \%$.

_ Se da la posibilidad de edificar vivienda colectiva: Se posibilita la construcción de edificios plurifamiliares siempre que respeten las distancias mínimas con los límites de parcelas y edificaciones vecinas, y se mantengan dentro las alturas máximas marcadas.

Esta innovación dentro de la ciudad jardín tradicional cambia radicalmente una de las bases que la hacían elitista, y permite reducir el precio de la vivienda. Es clara la reflexión sobre la vivienda colectiva que encaja perfectamente con el momento de turismo social que se 
vive desde mediados de los 50 . El abaratamiento de los costes, el aprovechamiento de los solares, o la seriación en la construcción influyen en el coste y precio de la residencia.

Es importante entender que pese a la base de ciudad jardín, los planes llegan de la mano de arquitectos y urbanistas influenciados por el Movimiento Moderno (Josep Claret Rubira). La nueva ciudad racionalista tiene una nueva relación con la naturaleza, la naturaleza y el artificio conviven sin problema en las teorías de Le Corbusier (La ville radieuse). La edificación se abre dejando pasar el verde y se produce una nueva concepción del espacio que se separa del convencional de calles y plazas.

Estos tejidos turísticos se convierten en edificios de apartamentos plurifamiliares, y crecen en altura o se densifican, pero siempre buscando una relación original y diferente entre el entorno y la construcción, siempre en búsqueda de las vistas. Y siempre conservando el cojín verde entre las edificaciones y la calle, sin marcar el límite de parcela.

Y la ciudad jardín cada vez se parece más a la ciudad racionalista, donde el verde fluye entre los edificios, y el jardín privado, aún sin pasar a ser público, va siendo cada vez más abierto y comunitario. Esta situación de encuentro entre dos modelos tan opuestos como son la ciudad jardín y la ville nouvelle, de alguna forma se encuentran en los planteamientos de la ciudad turística.

_ El paseo marítimo adquiere un carácter más peatonal:

Los paseos marítimos intentan acercar más el núcleo con la playa, eliminando el tránsito rodado en la medida de lo posible. En casos ex-novo como Platja d'Aro se convierten en completamente peatonales. Esta línea se acerca a los planteamientos que más tarde se expondrán en las estaciones turísticas del Languedoc Roussillon por G. Candillis y Jean Balladur, donde los principios del Movimiento Moderno toman todo el protagonismo en la costa y el paseo marítimo prácticamente desaparece, relacionando así al máximo las edificaciones con el mar. Estos nuevos planteamientos se alejan del papel relevante del paseo marítimo en las ciudades balneario, dónde éste marcaba un frente que separaba un delante y un detrás. 


\section{ID_INVESTIGACIONES}

\section{Presión Inmobiliaria}

Es, también, necesario mencionar el conocido papel que el negocio inmobiliario jugó la eclosión del fenómeno del turismo de masas. El rendimiento económico del suelo y la búsqueda de vistas, generan un aumento de densidades y crecimiento de alturas en las primeras líneas de mar, que se salen de los parámetros marcados en los planes. Y el marco normativo de los Planes Generales, no sólo no lo evita, si no que cede el paso a distintas ordenanzas municipales, y generales de la Provincia de Gerona que permiten e incitan a la subida de las alturas en el frente marítimo.

Durante los años 60 y 70 también se inician algunas urbanizaciones en terrenos de montaña con vistas al mar. Los terrenos económicos en estas zonas atraen a algunos inversores. Pero será al inicio de los años 80 , con la normativa que restringe las alturas en frente del mar, cuando las extensiones en montaña se densifican y se multiplican.

La presión inmobiliaria, por tanto, favorece el crecimiento en altura, la densificación de los núcleos, y el consumo de terreno rural para la creación de urbanizaciones.

\subsection{Los planes de los años 80 (1981-1987)}

Desde la Generalitat de Catalunya de la mano de Lluís Cantallops, Director General de Urbanismo, se decide poner en marcha el proceso de revisión del planeamiento general para controlar la situación y frenar el desmesurado crecimiento urbano.

En 1981 aparece el primer plan perteneciente a este conjunto, el Plan General de Blanes. Y año tras año se va completando toda la Costa Brava, Sant Feliu de Guíxols 1983, Torroella de Montgrí- Estartit 1983, Castell- Platja d’Aro 1985, Lloret de Mar 1985, Tossa de Mar 1986, Roses 1986, Calonge 1986, Palamós 1987, etc.

Estos planes, aparte de significar el inicio de la manera actual de hacer planeamiento y estudios urbanísticos, se proponen como objetivo la definición de un nuevo régimen urbanístico del suelo. Sus bases se plantean como solución de los problemas generados con los planes anteriores: 
_ Dotar a todos los núcleos turísticos de la infraestructura viaria y urbana necesaria, de la que no habían dispuesto hasta el momento.

_ Introducen más espacio público y equipamientos públicos utilitarios como escuelas, hospitales, etc.

_ Se clasifica el suelo de diferente manera, protegiendo las áreas rurales para frenar el crecimiento infinito de las décadas anteriores.

__ Se da continuidad a la "ciudad discontinua" que generan los primeros PGM.

_ Se estudia la protección de los núcleos históricos para acabar con la destrucción de su imagen.

_ Se regulan las alturas de los edificios eliminando definitivamente las facilidades que las ordenanzas municipales daban a la hora de construir en altura la primera línea de mar.

Estos planes fueron necesarios e imprescindibles para evitar la saturación de la costa.

\subsection{Problemática del nuevo tejido (desde el punto de vista de este estudio)}

El fuerte rechazo hacia las primeras actuaciones urbanísticas en la costa, hace que a la hora de formular los nuevos planteamientos se prescinda en exceso de las conclusiones y reflexiones tomadas en las décadas anteriores, y se den por nulos todos los modelos propuestos hasta el momento. Se rechaza el urbanismo y se proponen ideas que se referencian en modelos de ciudad que no tienen nada que ver con el turismo.

Analizando el resultado del planeamiento iniciado en los 80 , y comparándolo con el anterior, se detectan algunos problemas generados por este nuevo planteamiento cuya tendencia aún permanece en el planeamiento actual:

_ Se toma como base el modelo de ciudad convencional: Se analiza profundamente el territorio, y se plantea una normativa que construya ciudad, y que solucione la problemática evidente, pero se dejan de lado las aportaciones sobre la ciudad de vacaciones. La heterogeneidad de los tejidos turísticos existentes intenta ser paliada con un urbanismo que recoge la estructura de la ciudad convencional, olvidando las características que los 


\section{ID_INVESTIGACIONES}

tejidos turísticos ya poseían. En el fondo introducen un nuevo tipo de tejido que dará aún más heterogeneidad al conjunto.

_ Se pierde la relación especial entre los edificios y el entorno natural que genera la ciudad jardín, se forman calles: Se crean mallas urbanas ortogonales, en las que los edificios se ajustan a los límites de parcela y generalmente guardan espacios en el interior. Se marca el límite de las calles y la forma del vacío se acerca a lo urbano convencional. Este nuevo modelo que substituye las mallas turísticas de los años 60 , se utiliza tanto en el tejido turístico como en el industrial, es la base a la que conducirá el urbanismo en todo tipo de ciudad.

_ Se da continuidad a la ciudad, factor que en ocasiones también influye en la desvinculación de la edificación con la naturaleza: La falta de intención de crear ciudad y la discontinuidad que suponen los tejidos de los años 60 y 70 ha sido uno de las deficiencias a corregir desde el inicio de los años 80. Pero es contradictorio cuando nos damos cuenta de que muchos de los proyectos de los años 60 no pretenden crear "ciudad" en sentido tradicional, lo que proponen es una combinación entre naturaleza y edificación que sea equilibrada y no borre la huella natural.

En los años 90 y en la primera década del 2000 al frenarse la conquista de nuevos territorios a urbanizar, el planeamiento permite densificar las zonas ya construidas, sin tener en cuenta la esencia de sus proyectos iniciales. La re-urbanización de estas estructuras y la propuesta de continuidad hasta los núcleos existentes es básica para crear ciudad, pero la cuestiones: ¿hay que tratar el tejido turístico como si fuera una trama urbana convencional? ¿O hay retomar la base de sus propuestas iniciales para reflexionar sobre su apropiada corrección?

_ Desmesurada previsión de espacios públicos: No es lo mismo, hablar de espacio público en los núcleos de costa que en los núcleos interiores, el espacio público por excelencia de los primeros es la playa. En la planificación de los años 80 , no queda clara esta importancia, y se plantean grandes espacios interiores. Y la fuerza de la relación con el mar es tan grande, que en algunas ocasiones anula las grandes superficies vacías interiores convirtiéndolas en aparcamientos, o descampados. El espacio público en la costa va directamente relacionado con el reposo, como pasa con la playa, o con el ocio, como pasa con los vacíos relacionados con la actividad comercial.

La Costa Brava tiene la gran ventaja con respecto a otras zonas de playa, de que su paisaje 
y la típica postal de las bahías desde el mar, puede ser constantemente observado desde las peñas que se adentran en el mar como si de unos "piers" naturales se tratara. El Camino de Ronda mantiene el transito público.

_ En resumen, en el segundo periodo urbanístico se pierde la especificidad de la ciudad turística que sí existía en los tejidos urbanísticos del primer periodo, el tejido turístico de esta época se confunde con el resto de tejidos no turísticos.

Este retroceso tiene su paradoja en el paso de algunos de los modelos turísticos a las urbanizaciones de las ciudades industriales. La ciudad industrial y la ciudad turística se unen y se fusionan dejando la diferenciación entre ambas en detalles a una escala más pequeña.

En la producción arquitectónica también se pierde especificidad, la mezcla de principios racionalistas con las características del lugar, y la posterior experimentación con las formas curvas símbolo del reclamo turístico se quedan atrás para dar paso al pintoresquismo comercial o a la arquitectura urbana convencional.

\subsection{Comparativa con ejemplos entre los dos periodos (PGM 60's - PGM 80's)}

Los tejidos turísticos de los años 60 tienen un aspecto desordenado en el que se mezcla, sin una pauta clara, el verde con lo construido, los límites de las parcelas quedan difusos, y aunque la traza viaria siga un orden ortogonal.

En cambio se reconoce claramente un tejido turístico de los años 80 cuando la traza de la parcela se ve claramente marcada por el perímetro de sus edificios. Las manzanas son completamente ordenadas y marcan claramente el espacio público de la calle en el exterior y las zonas comunitarias privadas al interior. Se forma una trama perfectamente ordenada.

\section{Mallas turísticas}

En los años 60-70, estas tramas llamadas mallas turísticas se sitúan en los terrenos llanos frente al mar, de playas anexas a núcleos ya formados, o formando un nuevo núcleo. Se combinan casas unifamiliares con bloques plurifamiliares, que se convierten en torres de 
apartamentos al llegar a las primeras líneas de mar. Los edificios se centran en las vistas, en la posición de los apartamentos, y en la edificabilidad máxima. En las zonas posteriores se experimenta con las formas y las vistas al mar.

Ninguna de las edificaciones apoya en los límites de parcela, siempre guardan unas distancias mínimas que conservan el espacio verde junto a la calle, permiten que ésta respire, y hacen que un frente marítimo en el que se elevan múltiples edificaciones en altura no forme una barrera impermeable, dejando fluir la luz y el espacio entre las construcciones a la parte posterior.

Las mallas turísticas planteadas en los planes de los años 80 (imágenes de la derecha), también se sitúan en los tramos llanos. Pero la diferencia reside en que no sólo intentan ocupar las primeras líneas de mar sino que rellenan todos los vacíos de la discontinuidad de épocas anteriores sin tener como principal requisito las vistas. No es que éstas no resulten importantes y rentables, pero dado el éxito del boom turístico y la protección que adquieren los terrenos no edificados frente al mar, las mallas de esta época se adecuan a la nueva situación con segura rentabilidad demostrada en las décadas anteriores.

Se forman a partir de bloques de apartamentos creando manzanas abiertas y se aproximan al perímetro de la parcela, marcando las calles. Se consigue así un modelo mucho más cercano a la ciudad industrial.

Los nuevos bloques no superan generalmente la planta baja más cuatro o cinco pisos de altura, y reservan espacios comunitarios en el interior. El espacio abierto y de ocio privado comunitario, se privatiza aún más pasando al interior de la parcela, en la malla turística de
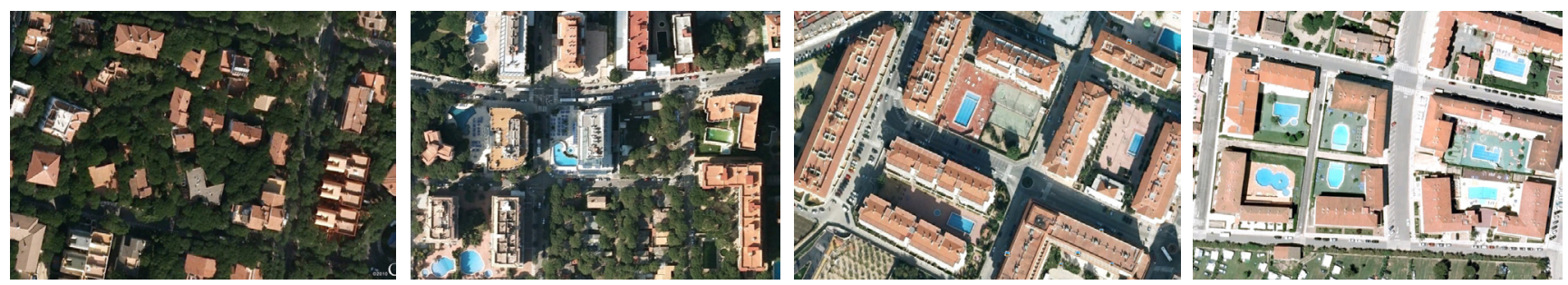
los 60 estas zonas comunitarias comparten el espacio abierto privado con la obertura de la calle.

\section{Urbanizaciones alrededor de un núcleo (plurifamiliares y unifamiliares)}

Las urbanizaciones de unifamiliares y bloques de apartamentos plurifamiliares que se inician en los años 60 se sitúan en vertientes de montaña buscando la buena orientación y las vistas al mar.

En el caso de las urbanizaciones con apartamentos plurifamiliares se aprovecha la compactación de las viviendas en horizontal o en altura para compensarlo con grandes espacios abiertos y equipamientos turísticos. La agrupación de la vivienda permite un constante contacto con la naturaleza de las edificaciones propuestas. Y a nivel arquitectónico se plantean diversas soluciones para conseguir el máximo disfrute de las vistas con la mayor privacidad posible entre apartamentos.

Las agrupaciones de apartamentos no tienen sentido en los años 60 sin los espacios verdes intersticiales y las grandes zonas verdes que las rodean. Pero durante los años 80 , muchas veces, estos espacios vacíos se confunden con discontinuidad y se construyen.

En las segundas imagen se puede ver casos desarrollados a partir de los años 80, proyectos de este tipo son completados hasta densificar el conjunto desproporcionalmente. El truco de compensar la concentración con espacios vacíos de los años 60 queda anulado por las posteriores actuaciones.

También se crean conjuntos de unifamiliares dispuestas de forma repetitiva y alineada

De izquierda a derecha: Politur, P.d'Aro 60-70's / Masnou P.d'Aro 60-70's / La Gavina, P.d'Aro 90 2000's / L'Escala, P.d'Aro 90-2000's.
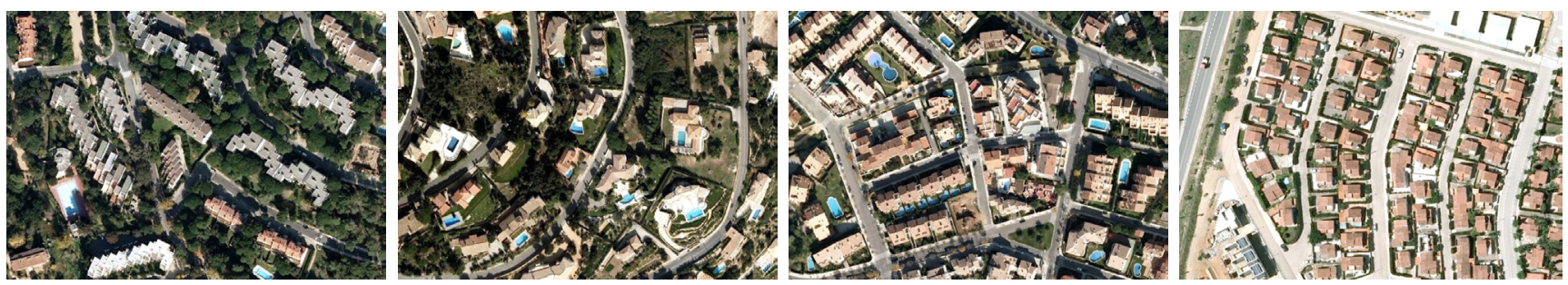


\section{ID_INVESTIGACIONES}

creando frentes y estructuras ortogonales virtuales que no tenían lugar en la irregularidad de las décadas posteriores. $Y$ tampoco se sitúan, ya en las vertientes de montañas con vistas al mar. Dada la gran demanda del sector turístico, las nuevas urbanizaciones se reparten en los alrededores de los núcleos sin dar importancia a la ubicación.

\section{CONCLUSIONES}

Hay que tener en cuenta la novedad que supone el fenómeno del turismo de masas y la falta de experiencia previa a la hora de proponer estructuras urbanas y conjuntos arquitectónicos para darle respuesta. Frente al reto de crear la residencia turística se recurre a la experimentación, la búsqueda de una nueva relación con la naturaleza y el reclamo turístico.

El territorio de costa, se expone como una serie de solares prácticamente vacíos donde no existe el peso histórico de las ciudades. $Y$ donde se llevarán a cabo muchos ensayos de los principios teóricos racionalistas que se dieron antes de la Guerra Civil (GATCPAC). Los territorios vacíos y un nuevo fenómeno al que dar respuesta urbana, no representaron un reto fácil a afrontar por los arquitectos de la época.

\section{Referencias Ciudad Jardín y Movimiento Moderno}

La ciudad jardín, había sido el gran referente durante el turismo de élite para urbanizar parajes naturales de costa. Sólo algunas propuestas promovidas por grupos como el GATCPAC se habían atrevido a plantear ciudades de vacaciones completamente racionalistas, como La ciutat del Repòs i les vacances (1931-1936) en Castelldefels, o el Poble d'Estiueig (1928) en la propia Costa Brava.

Se escoge el modelo clásico, la ciudad jardín, pero combinada con elementos racionalistas que la modifican.

La ciudad jardín se abre, permite la presencia de vivienda colectiva, convierte el jardín privado en zona comunitaria, y se acerca al planteamiento racionalista manteniendo siempre 
una relación especial entre el edificio y la parcela. Se acaba generando un modelo nuevo y diferente, la malla turística.

La culminación de este acercamiento del planeamiento de costa a los principios racionalistas, se produce pocos años más tarde en el desarrollo de las estaciones turísticas del Languedoc Roussillon. Los principios del Team10 serán fielmente aplicados por Georges Candillis en la estación de Port Leucate- Barcarès, y por Jean Balladur (de forma algo diferente) en La Grande Motte.

El Team10, o el Grup R en Catalunya, aplican los principios racionalistas de una forma más integrada a la realidad del territorio que intenta rebajar el carácter universal de los principios teóricos de los años 20. Pero de todas formas, en la costa francesa, la radicalidad de las propuestas y el absoluto rechazo a las ciudades turísticas clásicas como la ciudad jardín o la ciudad balneario, hace que se pierdan algunos elementos urbanísticos con propiedades turísticas interesantes.

En el caso de la Costa Brava, el hecho de ser un territorio de prueba sin previas experiencias claras, hace que a pesar del caos que se produce, se mantenga esa influencia mixta entre los planteamientos clásicos y los modernos.

\section{La transformación de núcleos históricos}

El crecimiento en altura no es lo mismo en el caso de los desarrollos ex-novo en forma de ciudad jardín, que los planteados sobre tejidos consolidados de ensanche o casco histórico. El problema de la Costa Brava fue que muchos de estos territorios vacíos rodeaban algún pequeño núcleo histórico, y las primeras planificaciones no supieron respetarlos. Su destrucción o su conservación dependía más de parámetros de accesibilidad al emplazamiento, que de estudios o normativas concretas que protegieran el patrimonio.

De esta manera, muchos núcleos antiguos fueron transformados, edificaciones históricas se convirtieron en bloques en altura. Esto sucede en muchos frentes marítimos como el de Blanes, Lloret, Sant Feliu de Guíxols, Palamós, etc.

Y en los casos donde las alturas en primera línea de mar parten de núcleos históricos existentes con estructuras de ensanches pese a que las edificaciones en primera línea de 


\section{ID_INVESTIGACIONES}

mar no lleguen a ser tan altas, sí que se forman barreras impermeables en primera línea de mar. La ciudad jardín absorbe de forma menos problemática el crecimiento en altura (Benidorm es un caso emblemático de cómo la normativa se adapta a la transformación para permitir el crecimiento en altura de toda la ciudad jardín)

\section{La especificidad del nuevo tejido turístico}

Una de las principales características que este tejido poseerá y lo separará del tejido de ciudad industrial, es la relación entre el edificio y su parcela, entre lo construido y el entorno. La ciudad jardín, pese a sus diferentes intensidades marcaba una separación mínima de lo construido con los límites de la parcela, y este es uno de los puntos que se mantiene en la construcción de tejidos turísticos. De este punto se deriva la no formación de calles tal y como habían sido entendidas en la ciudad industrial.

A parte de la posición de la edificación en la parcela, también se intuye en algunos proyectos la posición de los paquetes construidos con relación a los espacios naturales. En muchas ocasiones, la discontinuidad que se crea en este periodo, establece también relaciones especiales entre la edificación y la naturaleza.

A nivel arquitectónico, a pesar de que no es un sujeto tratado en este texto, pasa exactamente lo mismo. A partir de los años 80 se pierde toda la especificidad aportada por la experimentación de los años anteriores.

\section{No hay evolución en el planeamiento urbanístico desde los años 80}

El tejido turístico que se desarrolla durante los años 60 y 70 tiene un fuerte impacto sobre el territorio y la mayoría de las deficiencias que se le atribuyen desde la crítica de los años 80 son reales. Pero también es cierto que no se puede obviar lo construido y planeado durante dos décadas que marcaron un carácter imborrable en los núcleos de costa.

En los años 80 se hizo un gran trabajo para solucionar todos los problemas que se habían planteado, pero no se comprendió la esencia de los tejidos de costa, ni lo que los diferenciaba de la ciudad convencional. E introdujeron así un nuevo modelo de ciudad 
ordenada y continua pero que no correspondía con lo existente.

Pasado el tiempo, el planeamiento actual de la Costa Brava, sigue anclado a las mismas pautas que el que se desarrolla en los años 80 y las críticas siguen siendo las mismas. En la actualidad, la normativa urbanística no reconoce la identidad de los tejidos y ni de las arquitecturas de los años 60 y 70 , y por tanto sus especificidades no sólo no se mantienen sino que están siendo destruidas.

Si en los años 60 se produjo una desnaturalización del paisaje en favor de las nuevas arquitecturas turísticas, ¿no sería absurdo dejar caer en la banalidad y el deterioro todo aquello que se construyó en esa época? 


\section{BIBLIOGRAFÍA}

Libros

BARBAZÀ , YVETTE (1966) El Paisatge humà de la Costa Brava Vol.II. Barcelona: Edicions 62 abril 1988. (Le paysage humain de la Costa Brava. Edición original publicada en París 1966 Librarie Armand Colin)

DEBAT URBANÍSTIC SOBRE LA COSTA BRAVA (1978) Càmbra oficial de Comerç i Indústria Girona.

DEBAT URBANÍSTIC SOBRE LA COSTABRAVA(1989) Col•legi d'Arquitectes de Catalunya, Demarcació de Girona. 1990.

PIE NINOT, RICARD I BARBA I CASANOVAS, ROSA (1981) Castell d'Aro, Sant Feliu de Guíxols, Santa Cristina d'Aro 1981. Estudis Urbans. Generalitat de Catalunya, Departament de Política Territorial i obres públiques, Direcció General d’Urbanisme.

FERRER I AIXALA, AMADOR Y SABATÉ I BEL, JOAQUIM (1981) Torroella de Montgrí, I'Estartit 1981. Estudis Urbans. Generalitat de Catalunya, Departament de Política Territorial i obres públiques, Direcció General d'Urbanisme.

Diputació de Girona, Miratges, 300 anys de projectes no realitzats a les comarques gironines.

LAURENT COUDROY DE LILLE (textos)/ COL•LEGI D'ARQUITECTES DE CATALUNYA (1994) Ciutats de Girona : catàleg de plànols de les ciutats de Girona des del segle XVII al XX Demarcació de Girona : Diputació de Girona, 1994

UNLAND, ANNIE (1996) Llafranch entre la tradició i la modernitat. Diputació de Girona, Quaderns erns de Palafrugell.

BARRIS I RUSET, JOSEP MARIA (1999-2008) Roses o la recerca de la zona grisa. Roses: publicacions municipals.

Artículos

TATJER, MERCEDES (2009). En los orígenes del turismo litoral: los baños de mar y los balnearios marítimos en cataluña. Scripta Nova, Revista electrónica de Geografía y ciencias sociales. Universidad de Barcelona. Vol. XIII, núm 296 (5), 1 de Agosto de 2009. 
Sitios web

www.icc.es

www.diaridegirona.cat

\section{Consultas archivos:}

_ Archivos Municipales de: Roses, L’Escala, Palamós, Palafrugell, Platja d'Aro, Blanes , Lloret de Mar, Platja d'Aro.

Plan General de Ordenación, Blanes 1958

Plan general de Ordenación, La Escala 1956

Plan general de Ordenación, Rosas 1958

Plan General de Ordenación, Lloret 1957

Plan General de Ordenación de Palafrugell 1961

Plan General de Ordenación, Palamós, Sant Antonio de Calonge1959

Plan General de Ordenación Playa de Aro S'Agaró 1959

Proyecto de Urbanización de la Ciudadela de Roses, Nicolàs M. Rubió i Tudorí 1918.

Proyecto de Urbanización de la Plaza de Llafranch Isidre Bosch Batallé 1925.

_Archivo Histórico de Girona:

Fons de la Delegació Provincial de Girona del Ministeri de l'Habitatge (1947-1985) 


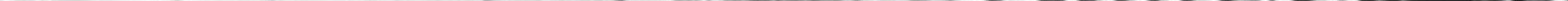

